\title{
COMPARISON OF EFFICACY OF PLAIN LIGNOCAINE WITH LIGNOCAINE AND CLONIDINE IN INTRAVENOUS REGIONAL ANAESTHESIA FOR UPPER LIMB SURGERY
}

Jyoti V. Kulkarni, Rashmi Bengali, Suhas Jewalikar.

1. Assistant Professor. Department of Anaesthesiology, Government Medical College, Aurangabad.
2. Associate Professor. Department of Anaesthesiology, Government Medical College, Aurangabad.
3. Professor. Department of Anaesthesiology, Government Medical College, Aurangabad.

\section{CORRESPONDING AUTHOR:}

Jyoti Vasantrao Kulkarni,

7, Bharat Nagar, Opp Indraprastha Enclave,

Jyoti Nagar, Aurangabad,

Maharashtra- 431005.

E-mail: jyotianil.joshi71@gmail.com

ABSTRACT: INTRODUCTION: IVRA is a simple, reliable, and effective technique with rapid onset of action, rapid and prompt recovery after tourniquet release. It provides good analgesia, adequate muscle relaxation, \& bloodless operative field. It is widely applicable to patients of different ages and physical status for operations \& cost effective. Lignocaine though preferred local anesthetic agent has limitation of short duration of anesthesia \& inability to provide postoperative analgesia various additives were added to it. In this study we compared efficacy of clonidine as an adjuvant to lignocaine with plain Lignocaine. MATERIAL \& METHOD: Patients undergoing upper arm surgery were included in this study \& are divided in two groups. The proximal circulatory isolation of arm was done by placing a pneumatic tourniquet around arm. In group C IVRA was given by $1 \mathrm{ug} / \mathrm{kg}$ clonidine $\& 0.5 \%$ preservative free lignocaine in a dose of $200 \mathrm{mg}$ diluted up to $40 \mathrm{ml} \&$ in group L $0.5 \%$ preservative free lignocaine $200 \mathrm{mg}$ diluted up to $40 \mathrm{ml}$. Tourniquet was deflated at least 30 mines after injection of drug. AIMS \& OBJECTIVES: To compare onset and quality of sensory analgesia, Onset and quality of motor blockade, onset \& severity of tourniquet pain, Complications like hypotension \&bradycardia during the procedure, recovery from sensory and motor blockade duration of Postoperative analgesia in group $\mathrm{C}$ with group L. CONCLUSION: We observed that using Clonidine in dose of 1 ug/kg as an adjuvant to Lignocaine in IVRA does not have early onset of sensory blockade, increased tourniquet tolerance, delayed tourniquet pain and extended post-operative analgesia .Neither systemic side effects like nausea, bradycardia, hypotension, convulsion nor local complications like hematoma were observed.

INTRODUCTION: Intravenous regional anaesthesia was originally introduced by the German surgeon August K. G. Bier ${ }^{1}$ in 1908; thus the name, "Bier block". Dr. Bier described a complete anaesthesia and motor paralysis after intravenous injection of Prilocaine into a previously exsanguinated limb. It is a simple, reliable, and effective technique with rapid onset of action, and prompt recovery after tourniquet release. It provides good analgesia, adequate muscle relaxation, \& bloodless operative field, widely applicable to patients of different ages and physical status for operations \& cost effective. Poor postoperative analgesia, limited duration of anaesthesia ( $<90$ minutes), the potential for local anesthetic toxicity, nerve damage and compartment syndrome are the disadvantages of intravenous regional anaesthesia. 
Various studies are carried out using adjuvant to the local anesthetics solution to improve quality of analgesia in intravenous regional anaesthesia .Adjuvant like Ketamine, Meperidine, Morphine, Sufentanil, Ketorolac, Tramadol, Clonidine, Dexmedetomidine, Magnesium sulphate, Pancuronium, Nitroglycerine has been used. Clonidine is a centrally acting alpha-2 agonist having sedative property. It improves intraoperative stability by reducing catecholamine release and decreases post- operative analgesic requirement. In peripheral nerve blocks, it prolongs the duration of block. Side effects include bradycardia, hypotension, sedation, dry mouth, respiratory depression.

In our study we added $1 \mathrm{ug} / \mathrm{kg}(1 \mathrm{ml})$ Clonidine to preservative free $0.5 \%$ Lignocaine 200mg diluted up to $40 \mathrm{ml}$ (Group C) and compared it with $0.5 \%$ preservative free lignocaine $200 \mathrm{mg}$ diluted up to $40 \mathrm{ml}$ plus $1 \mathrm{ml}$ normal saline (Group L).

AIMS AND OBJECTIVES: This study was conducted in 60 patients undergoing forearm surgeries in orthopedic department. We compared the efficacy of clonidine $1 \mathrm{ug} / \mathrm{kg}$ added to 0.5 \% Lignocaine with $0.5 \%$ Lignocaine for intravenous regional anaesthesia. We compared onset of sensory blockade and motor blockade, intensity of tourniquet pain, intraoperative complications, duration of postoperative analgesia and number of analgesic doses required within first $24 \mathrm{hrs}$ in both groups.

MATERIAL \& METHOD: After approval of hospital ethical committee, this study was conducted in 60 patients posted for upper limb surgery. Patients were randomized in 2 groups by computer generated randomization with 30 patients in each. Patients with age 15-50 years, ASA grade I and II, weight $50-60 \mathrm{~kg}$ were included in this study. Patients with sickle cell disease, peripheral vascular disease, hemolytic disease, refusal for regional block, hypersensitivity to Lignocaine or Clonidine, major systemic illness \& local infection were excluded from the study. All equipment's and drugs necessary for resuscitation and general anaesthesia were kept ready. Continuous Electrocardiogram, noninvasive blood pressure, and pulse oximeter were used for monitoring. Pulse rate, mean arterial pressure (MAP) respiratory rate, Sp02 (peripheral $\mathrm{O}_{2}$ saturation) were noted. A tourniquet was placed on the arm to be blocked. We used a "double cuff" tourniquet was used to increase the reliability of the technique and reduce the tourniquet pain.

A 22-gaug intravenous cannula was introduced in the dorsum of the hand to be anesthetized. The arm was elevated for 3-5 minutes to allow passive exsanguination. On the opposite hand a 20 gauge intravenous cannula was put for crystalloid infusion intraoperatively at a rate of $4 \mathrm{ml} / \mathrm{kg} / \mathrm{hr}$. Patient received intravenous Midazolam $1 \mathrm{mg}$ and Fentanyl $100 \mu \mathrm{gm}$ as premedication. Pneumatic double cuff tourniquet was placed around the upper arm, and the proximal circulatory isolation of arm was verified by inspection, absence of radial pulse, loss of pulse oximetry reading in ipsilateral index finger.

In patients from GROUP L 200mg of Lignocaine was diluted with normal saline up to 41 $\mathrm{ml} \&$ in GROUP C $1 \mathrm{ug} / \mathrm{kg}$ clonidine and 200mg of Lignocaine was diluted with normal saline up to $40 \mathrm{ml}$ (total volume of $41 \mathrm{ml}$ ). The solution was injected over 90 seconds in the hand to be operated. Sensory block was assessed by pinprick with $22 \mathrm{G}$ short bevelled needle every 30 seconds. Patient's response was evaluated in the dermatomal sensory distribution of medial and lateral brachial cutaneous, ulnar (little finger, hypothenar eminence), median (thenar eminence, index finger) and radial (forearm and first web space) nerves. 
Sensory block was graded as Gr. 4-excellent with no pain, Gr. 3-minor pain with no need of supplemental analgesic, Gr.2-moderate pain needed supplemental analgesics (Fentanyl $1 \mu \mathrm{g} / \mathrm{kg}$ ), Gr.-1-severe pain (General anaesthesia needed). Motor function was assessed by asking the subject to flex and extend his fingers, wrists and elbow and was graded according to Bromage scale. Time required for motor paralysis was defined as time elapsed from injection of study drug to complete motor block. Motor block was graded as Grade 4 - no movement, Grade 3 - movement only at interphalangeal joint, Grade 2 -movement at interphalangeal and wrist joint, Grade 1 - movement at interphalangeal, wrist and elbow joint.

After sensory and motor blockade, the distal tourniquet was inflated to $100 \mathrm{mmHg}$ above systolic blood pressure, the proximal tourniquet was released, and surgery was started. MAP( mean arterial pressure), HR (heart rate), $\mathrm{SpO}_{2}$ were monitored immediately after distal tourniquet inflation and 5, 10, 15, 20, 30, 40 and 50 min after injection of anaesthetic and after release of tourniquet.

Assessment of tourniquet pain was made by visual analogue scale (0-no pain and 10worst pain imaginable) measured before and after tourniquet application and 5,10,15,20,30,40 and 50 min after study drug application. With VAS(visual analogue scale) more than 4, Inj Fentanyl $1 \mu \mathrm{g} / \mathrm{kg}$ was given to reduce pain. Changes in heart rate and blood pressure $(25 \%$ decrease or increase from baseline) were considered significant. Treatment for bradycardia, tachycardia \& hypotension and decrease $\mathrm{SpO}_{2}$ if noted was started immediately. The tourniquet was deflated 30 minutes after injection of drug and not kept inflated for more than 90 mints.

At the end of surgery tourniquet was deflated by intermittent cuff deflation re-inflation technique which was repeated for 3times at 10 seconds interval. Sensory recovery time was noted (time elapsed from tourniquet deflation to recovery of sensation in all dermatomes, determined by pinprick test).Motor block recovery time was noted (time elapsed from tourniquet deflation to movement of fingers, hand and forearm).Postoperative analgesia was assessed every 15 minutes as per VAS(visual analogue scale) in the first hour and later every one hour till score was 4 or more. The first analgesic requirement time was noted (time elapsed from tourniquet release until first patient request for analgesic)

Data was analysed by Student's t tests and Chi square test. The data which included the hemodynamic parameters, Sp02, duration of analgesia were calculated and compared with baseline values within each group using the software 'GraphpadPrism5'. For comparing quantitative data between the study groups unpaired ' $t$ 'test was applied. Comparison of nonparametric (qualitative) data between the study groups was done using Chi-square test, Chisquare test for trend and Fisher Exact test depending on types of data. Statistical significance is indicated by conventional symbols: ${ }^{*} \mathrm{P}<0.05$ :Statisticallysignificant ${ }^{*} \mathrm{P}>0.05$ : Statisticallynon significant

RESULT: Demographic data for age, sex and weight was comparable in both groups of patients. Onset of sensory blockade was earlier $(281 \pm 72.84$ seconds) in group C than in group L (382 \pm 74.80 seconds). The difference in mean time of onset of sensory block between group $\mathrm{L}$ and group $C$ was statistically significant $(\mathrm{p}<0.001)$. The difference in mean time of onset of motor block between group L $(637.33 \pm 115.63$ seconds) \& group C $(579 \pm 130.65$ seconds) was not significant $(\mathrm{p}>0.05)$. Patients in group $\mathrm{C}$ had better tolerance of tourniquet than those of group L. No rescue analgesic was required in group $\mathrm{C}$ while five patients from group L required Inj. Fentanyl \& one patient required supplementation of Inj. Ketamine intraoperatively. Better intraoperative cardiac stability was observed in Group C, as compared to Group L. 
Onset of pain after release of tourniquet in group C was significantly prolonged than in Group L. All patients from group L had pain within 2 hours after the release of tourniquet while the patients from group $\mathrm{C}$ had pain after 2 hours of release of tourniquet. All patients from group $\mathrm{L}$ and only5 patients in $\mathrm{C}$ group required analgesics within first $4 \mathrm{hrs}$. and patients from group $\mathrm{C}$ experienced prolonged analgesia and subjective comfort. Mean time for first analgesic consumption in group L was $99.034 \pm 28.11$ min. and in group C it was $371.66 \pm 172.58$ mints. Better intraoperative cardiac stability was observed in group $\mathrm{C}$ as compared to group L.

The mean recovery time of sensory and motor blocks was comparable in both the groups. Patients from group L required earlier postoperative supplementation of analgesics. Out of 30 patients in group C 5(15.66\%) patients required analgesics during first 4 hrs., $9(30 \%)$ patients required analgesics during first 8 hrs. remaining 13(43.33\%) required analgesics after 8 hrs. postoperatively. We did not observe any complications like bradycardia, nausea, vomiting, sedation, convulsions, light headedness, hypotension in either group.

DISCUSSION: Adjuvant is added to local anaesthetic solution in intravenous regional anaesthesia to improve quality of block, prolong post- operative analgesia and decreases tourniquet pain. Clonidine, Dexmedetomidine, Fentanyl, Ketorolac, Tramadol, Nitroglycerine, Dexamethasone, Magnesium sulphate, Sufentanil and Pancuronium has been used so far in intravenous regional anaesthesia as an adjuvant. Data from several clinical investigations support the importance of peripheral adrenergic receptors in the maintenance of sympathetically maintained pain. It was supported by the observations like adrenergic blockade with intravenously administered phentolamine, phenoxybenzamine, or prazosin diminishes pain.2intravenous regional anaesthesia with guanethidine depletes peripheral catecholamine and can relieve sympathetically maintained pain, intradermal injection of norepinephrine rekindles sympathetically maintained pain in patients who have previously undergone sympathectomy and topical application of clonidine has been shown to eliminate hyperalgesia only at the site of drug application. ${ }^{2}$

Clonidine is alpha 2 -adrenergic agonist that can affect both central and peripheral adrenergic receptors ${ }^{2}$. Clonidine reduces release of norepinephrine from pre-junctional alpha 2 -adrenoreceptors in the periphery hence reduces sympathetically maintained pain.,3 It was observed that sympathetic neural activity might increase pain associated with skin damage. Clonidine inhibits the release of Norepinephrine from prejunctional $\alpha 2$-adrenoceptors in the periphery \& potentially inhibits neural activity in nociceptive pathways ${ }^{4}$ It acts by selectively blocking conduction of A- $\delta$ and $C$ fibres and also causes local vasoconstriction, thereby reducing the vascular uptake of local anaesthetics. Clonidine may produce a peripheral analgesic effect by releasing encephalin-like substances. Perineural administration of the Clonidine is also known to prolong duration of analgesia due to depression of nerve action potentials especially in $\mathrm{C}$ fibres. Clonidine has shown greater analgesic potential with minimal adverse effects with a dose of up to $150 \mu \mathrm{g}^{5}$. Adverse effects of Clonidine are sedation, hypotension, and bradycardia 5 . Clonidine has several clinically desirable effects such as, anxiolysis, anaesthetic sparing and cardiovascular stabilizing property. It reduces intraocular pressure \& salivary secretion.

It was observed that maximum hypotensive and sedative effects usually occur with concentrations of clonidine in plasma between 1.5 and $2.0 \mu \mathrm{g} / \mathrm{ml} .^{2}$ This might be due to the fact that plasma concentrations of clonidine $(0.12 \pm 0.05 \mu \mathrm{g} / \mathrm{ml})$ obtained $30 \mathrm{~min}$ after deflation of the tourniquet was significantly lower than those required for a central sympatholytic effect. Higher doses of Clonidine may provide prolonged analgesia at the expense of excessive 
sedation, bradycardia, and hypotension. This is seen especially when Clonidine is used in a dose $>2 \mu \mathrm{g} / \mathrm{kg}$. Hence we preferred the dose of Clonidine as $1 \mathrm{ug} / \mathrm{kg}$ and did not observe any adverse effect.

Gentili $\mathrm{M}$ and et al observed that verbal rating scores for tourniquet pain at 15,30,\& 45 min for Clonidine group was significantly lower than plain Lignocaine group. ${ }^{3}$ Our observations match with above findings. Ruben Scott et al compared $1 \mu \mathrm{g} / \mathrm{kg}$ intravenous Clonidine with 1 $\mu \mathrm{g} / \mathrm{kg}$ Clonidine added to the intravenous regional anaesthesia solution. They observed that patients in the clonidine group had a significantly longer period of subjective comfort and they didn't require any analgesics ${ }^{3}$. We observed decrease in mean blood pressure and heart rate by approximately $15-20 \%$, which was subsided within 2-4 h postoperatively without rescue drug and reduced dose requirements of analgesic drug.

Guanethidine if added to Lignocaine produces prolonged hypotension, apnoea, and angina. ${ }^{6}$ Opiates Fentanyl, Morphine, Sufentanil and Meperidine can be added to Lignocaine but known to produce nausea, vomiting, and dizziness. ${ }^{6}$ To achieve good quality of motor block atracurium or pancuronium was added to Lignocaine but muscle weakness lasts for several hours after use of Atracurium 6,7

Neil Roy Connellya had assessed the analgesic efficacy of administering Lidocaine and Ketorolac with either a forearm or upper arm tourniquet for outpatient hand surgery ${ }^{8}$. He found that forearm tourniquet technique results in a longer duration of sensory block and prolonged postoperative analgesia compared with upper arm intravenous regional anaesthesia while using half the doses of both drugs - Ketorolac was known to cause hematomas at the injection site $^{8}$.

Intravenous regional anaesthesia block with bretylium had used but was discontinued because of the high incidence of orthostatic hypotension which prevented the discharge of patients from the outpatient clinic. Bevinagidad Veerappa tried Fentanyl \& Tramadol as an adjuvant to Lignocaine for intravenous regional anaesthesia for upper limb surgery\& concluded that Tramadol provides significantly longer post- operative analgesia as compared to Fentanyl added to Lignocaine in surgeries of upper limb ${ }^{9}$.

Lignocaine is the most widely used local anaesthetic for intravenous regional anaesthesia due to safe, rapid onset of analgesia, good muscle relaxation, prompt recovery, less cardio toxicity \& minimal neurological sequel as compared to other local anaesthetic drugs ${ }^{6,10}$, Chlorprocaine produced thrombophlebitis due damage to vascular endothelium leading to pain on administration 6, Prilocaine produced methemoglobinemia and its stability cannot be guaranteed if diluted with less incidence of central nervous system toxicity. ${ }^{6}$ Ware used Bupivacaine for intravenous regional anaesthesia IVRA and found that Bupivacaine was associated with several toxic reactions, cardiac arrest in form of ventricular fibrillation.11,6Maxmillan et al used Ropivacaine, and found good intraoperative(2hrs) and postoperative analgesia. ${ }^{12,6}$ Articaine produces erythematous rash in the area where drug is injected ${ }^{6}$.

Ketamine was also used as sole agent for intravenous regional anaesthesia. Ketamine was known to produce loss of consciousness, hallucinations and unpleasant psycho mimetic effectS13, 6, Meperidine was known to develop of dizziness, nausea, pain at the injection site, flushing of face, corneal injection and throbbing headache ${ }^{13}$.Hence these drugs are not used routinely for intravenous regional anaesthesia. Magnesium sulphate as an adjuvant produce faster onset of sensory and motor blockade as compare to ketorolac ${ }^{14} .200 \mu \mathrm{gm}$ Nitroglycerine 
added to lignocaine lead to early onset of sensory and motor block with prolonged postoperative analgesia without any adverse effect 15

Success of intravenous regional anaesthesia needs exsanguination of limb at least for5 min, use of double bladder cuff tourniquet and tourniquet deflation by intermittent cuff deflation re-inflation technique. Maximum allowable tourniquet time for upper limb is 60 to 90 minute. Inflation of tourniquet beyond this period results in complications like tourniquet pain, nerve injury, post- operative oedema of, pressure sores and thrombosis. Use of Lignocaine with Clonidine was useful for early onset of sensory block and prolongation of analgesia.

CONCLUSION: Using Clonidine in dose of $1 \mu \mathrm{g} / \mathrm{kg}$ as an adjuvant to Lignocaine in intravenous regional anaesthesia IVRA has, early onset of sensory blockade, delayed the onset of tourniquet pain, increased tourniquet tolerance, reduced severity of tourniquet pain and extended postoperative analgesia. No effect on onset of motor blockade was observed. No adverse effects like nausea, bradycardia, sedation, hypotension and convulsion or local complications like hematoma were observed. When administered as part of a regional anaesthetic, Clonidine surely prolongs anaesthesia and analgesia in a dose-dependent manner.

\section{BIBLIOGRAPHY:}

1. Millersanesthesia; 6th edition (Indian edition)2005; volume II; Ronald D Miller,; first edition 1981; chapter no. 44; NERVE BLOCKS; Denise J;Wedel and Terese T Horlocker Page no. 1686-1715

2. Reuben, Scott S, Steinbergetal Intravenous Regional Clonidine in the Management of Sympathetically Maintained Pain; Anesthesiology; August 1998 ;89; (2); 527-530

3. Gentili $\mathrm{M}$, Bernard J Mona RoofatFahmetetal The addition of clonidine $0.2 \%$ and Lidocaine $0.5 \%$ for intravenous regional anaesthesa prevents tourniquet pain ; AnesthAnalg 1999;89; (3):727-31

4. Eisenach, James C; De Kocketal Clonidine as an adjuvant to local anesthetic agent for intravenous regional anesthesia Anesthesiology: Sept1996 ; 85;( 30 ); 655-74

5. Damien B. Murphy, Colin J. L. McCartney etal Novel Analgesic Adjuncts for Brachial Plexus Block: A Systematic Review ;AnesthAnalg 2000;90: 1122-8

6. Complications of regional anesthesia; Brendan T, Finucane ; 2nd edition2008; Dominic A Cave , Barry A Finegan, , Chapter No. 12, complications of Intra venous regional anaesthesia.

7. F.Rodol, S.Vangnonsetal; An update on IntavenousAnesthesia, Anesthesiologia e Rianimizione, Catholic University Sacrocuore-RomeItal2003;7:131-138

8. Neil Roy Connellya, Scott Reubena; Intravenous Regional Anesthesia with KetorolacLidocaine for the Management of Sympathetically-Mediated Pain . Yale Journalof Biologyand Medicine 68 (1995), pp. 95-99

9. Bevinagidad, Veerappa G; One Year Randomized Controlled Trial Of Fentanyl And Tramadol As Adjuvants To Lignocaine For Intravenous Regional Anaesthesia For Upper Limb Surgery. Issue Date: Sep-2006 URI: http://hdl.handle.net/123456789/2791 Appears in Collections: Anesthesiology 
10. Fleming S.A.: Safety and Usefulness of Intravenoius Regional Anaesthesia Acta.Anaesth.Scand., 36(suppl.)21,1969.

11. Ware R J. Intravenous regional anesthesia using bupivacaine: A double blind comparison with lignocaine;Anesth1979:34:231

12 Maximilian W. B. Hartmannsgruberetal ;Comparison of Ropivacaine $0.2 \%$ and Lidocaine 0.5\% for intravenous regional anesthesia in volunteers; AnesthAnalg 1999;89:727-31

13 Durrani Z, Winnie AP etal; Ketamine for intravenous regional anesthesia;

Anesth. Analg 1989;68:328-32

14 Smnath Bose, Rani A.Sunderetal Study of magnesium , ketamine, ketorolac as adjuvant to lignocaine in intravenous regional anaesthesia Anaesthesiology 2008:109, A555

15 RahmanAbbasivash, EbrahimHassnietal ; Nitroglycerineas an adjuvant to Lignocaine ; Middle East Journal of anesthesiology ; 07/2009:20(2);265-9

$\underline{\text { Table } 1}$

\begin{tabular}{|l|l|l|l|l|}
\hline $\begin{array}{l}\text { sr } \\
\text { no. }\end{array}$ & parameter & group l & group c & p value \\
\hline 1 & age & $35.83 \pm 11.92$ & $36.20 \pm 14.33$ & $0.9146^{*}$ \\
\hline 2 & weight & $58.60 \pm 4.415$ & $56.97 \pm 5.411$ & $0.2053^{*}$ \\
\hline 3 & sex(m:f) & $20: 10$ & $23: 7$ & $0.5675^{\$}$ \\
\hline 4 & onset of sensory block & $382 \pm 74.80$ seconds & $281 \pm 72.84$ seconds & p $<0.001^{*}$ \\
\hline 5 & onset ofmotor block & $637.33 \pm 115.63$ seconds & $579 \pm 130.65$ seconds & p $<0.05^{*}$ \\
\hline 6 & duration of surgery & 60.36 min & 58.01 min & \\
\hline 7 & tourniquet pain & $\begin{array}{l}5 \text { patients needed rescue } \\
\text { analgesics }\end{array}$ & $\begin{array}{l}\text { rescue analgesics not } \\
\text { needed }\end{array}$ & \\
\hline 8 & $\begin{array}{l}\text { time of requirement of } \\
\text { first analgesic }\end{array}$ & $\begin{array}{l}99.034 \pm 28.11 \\
\text { min. }\end{array}$ & $\begin{array}{l}371.66 \pm 172.58 \\
\text { min }\end{array}$ & $\mathrm{p}<0.001$ \\
\hline 9 & $\begin{array}{l}\text { intraoperative } \\
\text { complications } \\
\text { pain } \\
\text { nausea \& vomiting }\end{array}$ & $\begin{array}{l}1 \\
1\end{array}$ & \\
\hline
\end{tabular}

Table II table showing number of patients who required analgesic doses in first $24 \mathrm{hrs}$

\begin{tabular}{|l|l|l|}
\hline Duration & $\begin{array}{l}\text { No of patients required 1 } \\
\text { analgesic dose in Group L }\end{array}$ & $\begin{array}{l}\text { No of patients required analgesic } \\
\text { dose in Group C }\end{array}$ \\
\hline $0-4 \mathrm{hrs}$ & 30 & 8 \\
\hline $4-8 \mathrm{hrs}$ & - & 9 \\
\hline$>8 \mathrm{hrs}$ & - & 13 \\
\hline
\end{tabular}




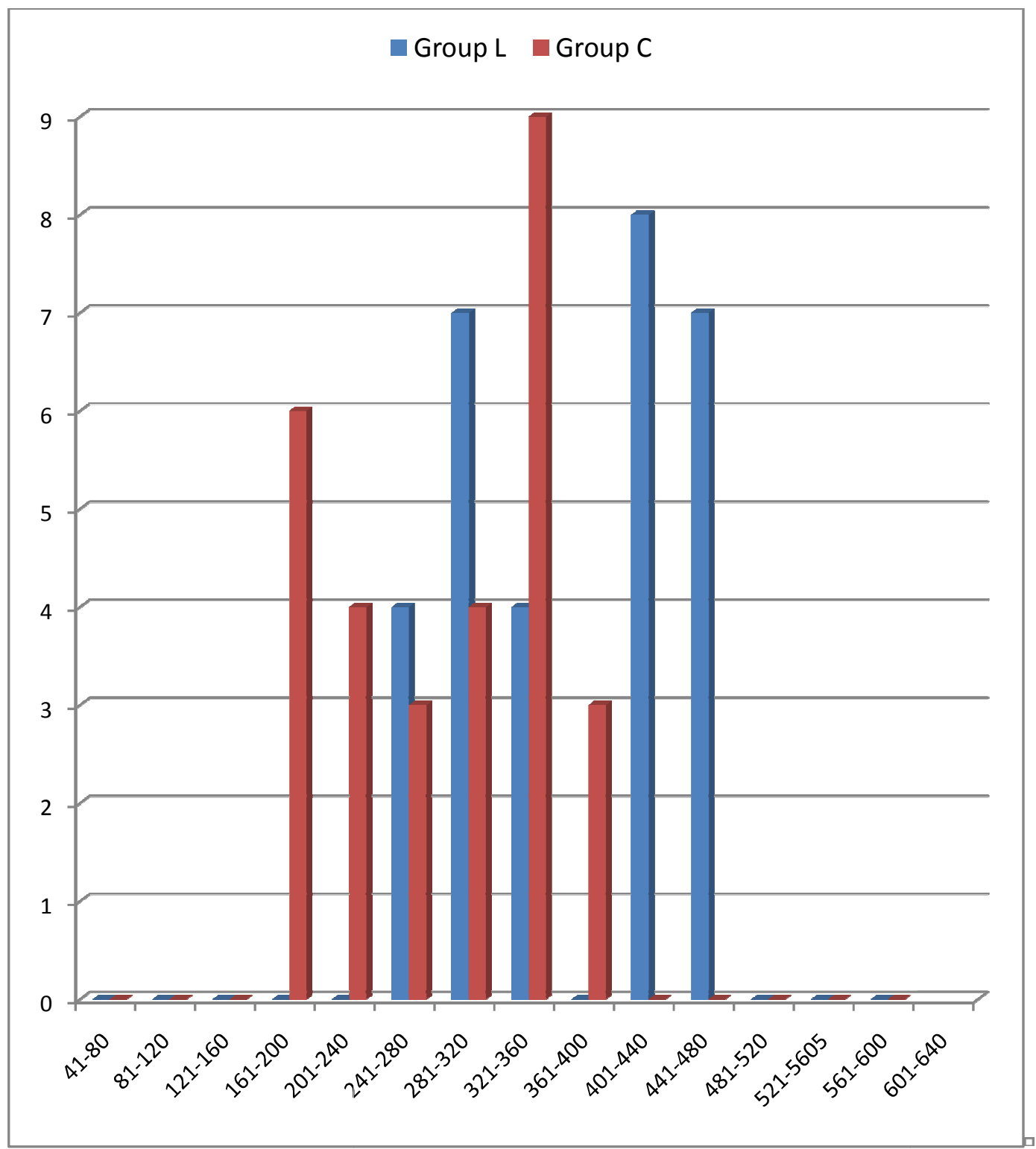

\section{GRAPH SHOWING TIME OF ONSET OF SENSORY BLOCKADE}

$\mathrm{X}$-axis-Time of onset of sensory blockade in seconds.

Y-axis- Number of patients.

The difference in mean time of onset of sensory block between group L \& group C was

Fount to be significant $(\mathrm{p}<0.001)$ 


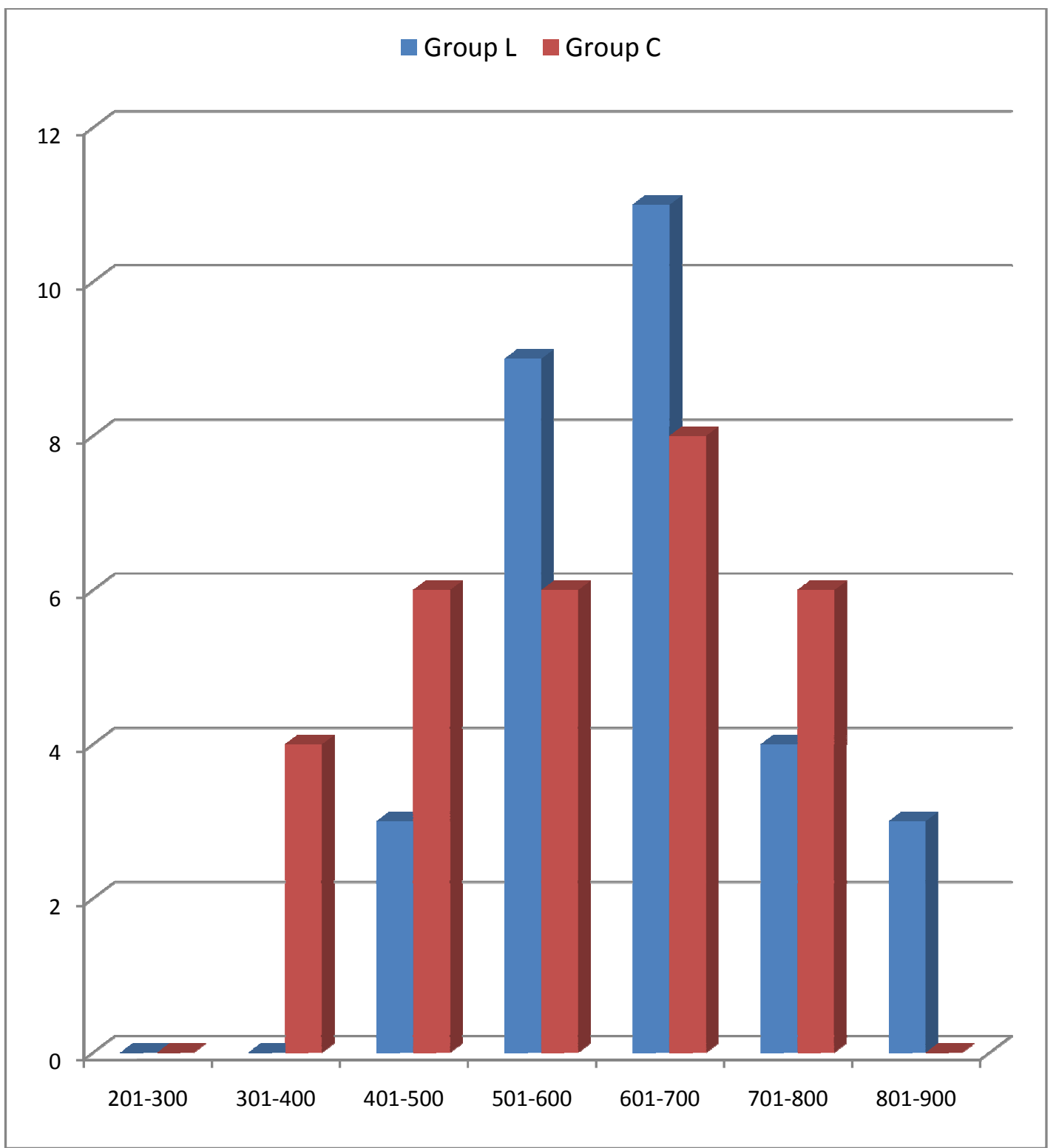

\section{GRAPH SHOWING TIME OF ONSET OF MOTOR PARALYSIS}

$\mathrm{X}$ axis-Time of onset of motor paralysis in Seconds.

$\mathrm{Y}$ axis-Number of patients.

The difference in mean time of onset of motor block between group L \& group C was found to be non significant $(\mathrm{p}>0.05)$ 


\section{ORIGINAL ARTICLE}

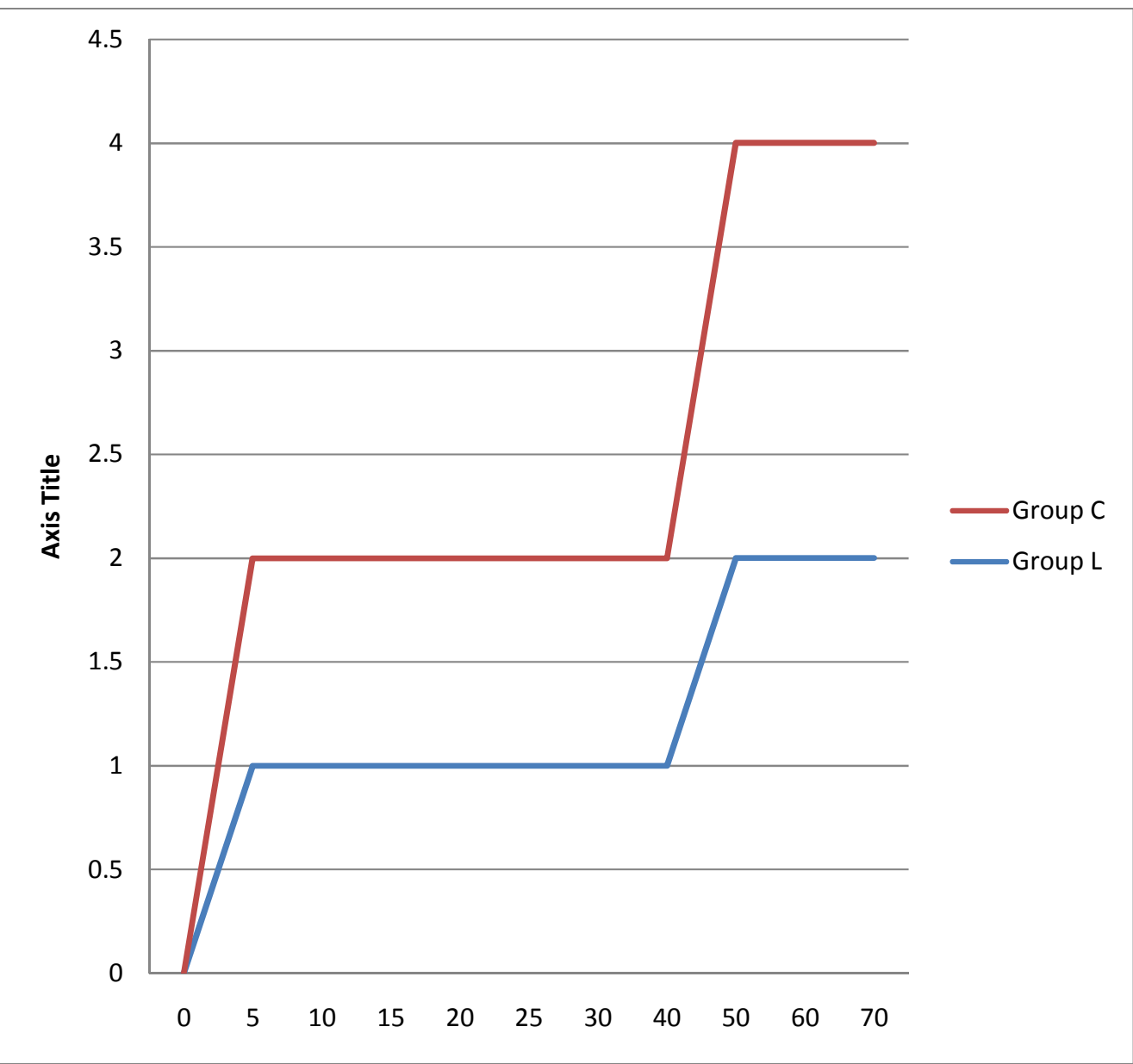

\section{CHART SHOWING SEVERITY OF TOURNIQUET PAIN BY VAS}

(VISUAL ANALOGUE SCORE).

$\mathrm{X}$ - axis- showing time in minutes.

$Y$ axis- showing median range of VAS.

The tourniquet pain was comparable in both the groups during first $70 \mathrm{~min}$. of surgery. No significant difference found between two groups. $(p>0.05)$ 


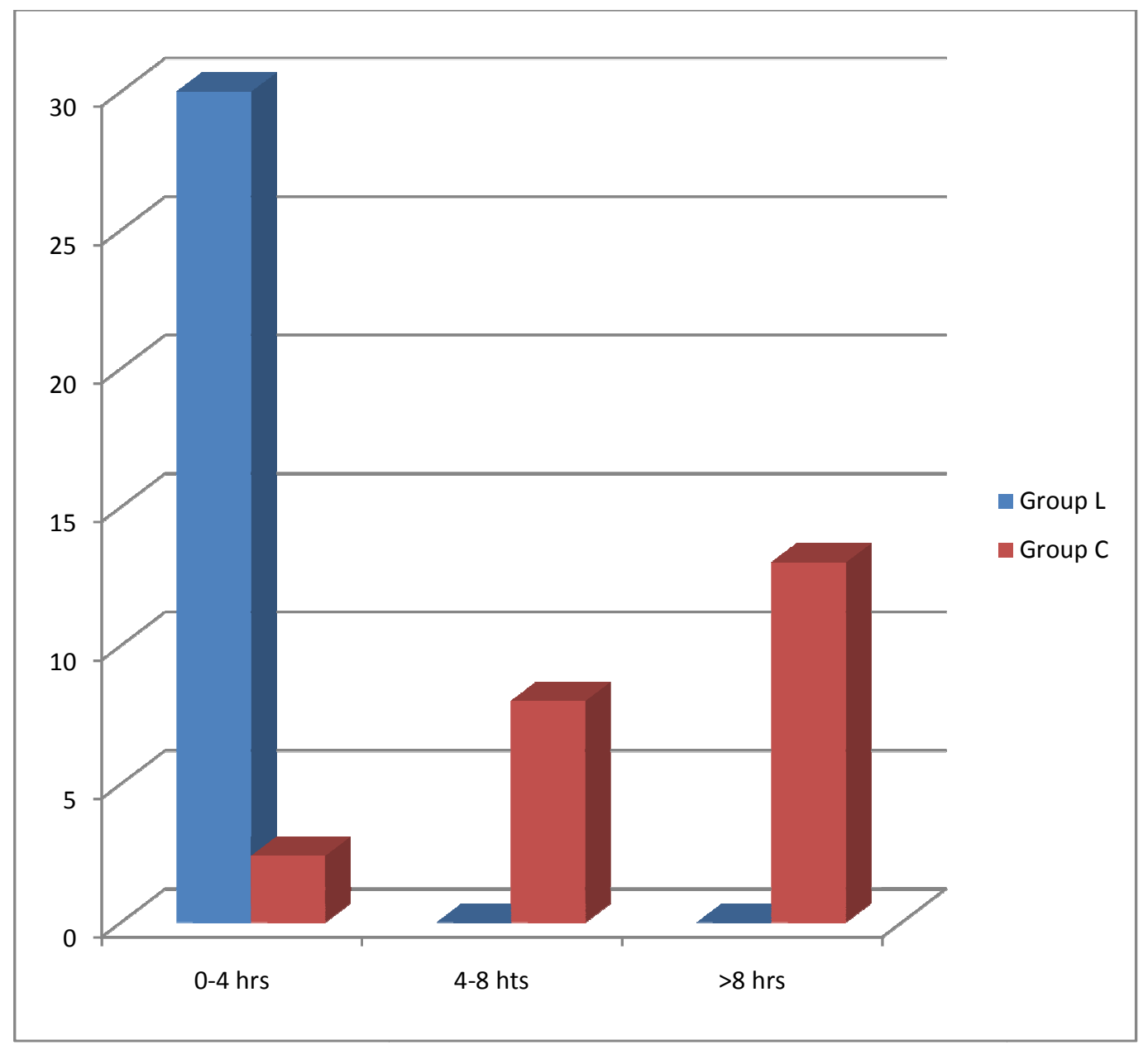

GRAPH SHOWING NO.OF PATIENTS WHO REQUIRED ANALGESIC TABLETS IN FIRST 24 HRS.

$\mathrm{X}$ axis - showing postoperative period in hrs.

$\mathrm{Y}$ axis - showing Number of patients, who required post operative analgesic tablets postoperatively.

As from above all patients from group L required analgesia within first 4 hrs as compared to 5 patients in $\mathrm{C}$ group. Patients from Clonidine group experienced prolonged analgesia \& subjective comfort than Group L 


\section{ORIGINAL ARTICLE}

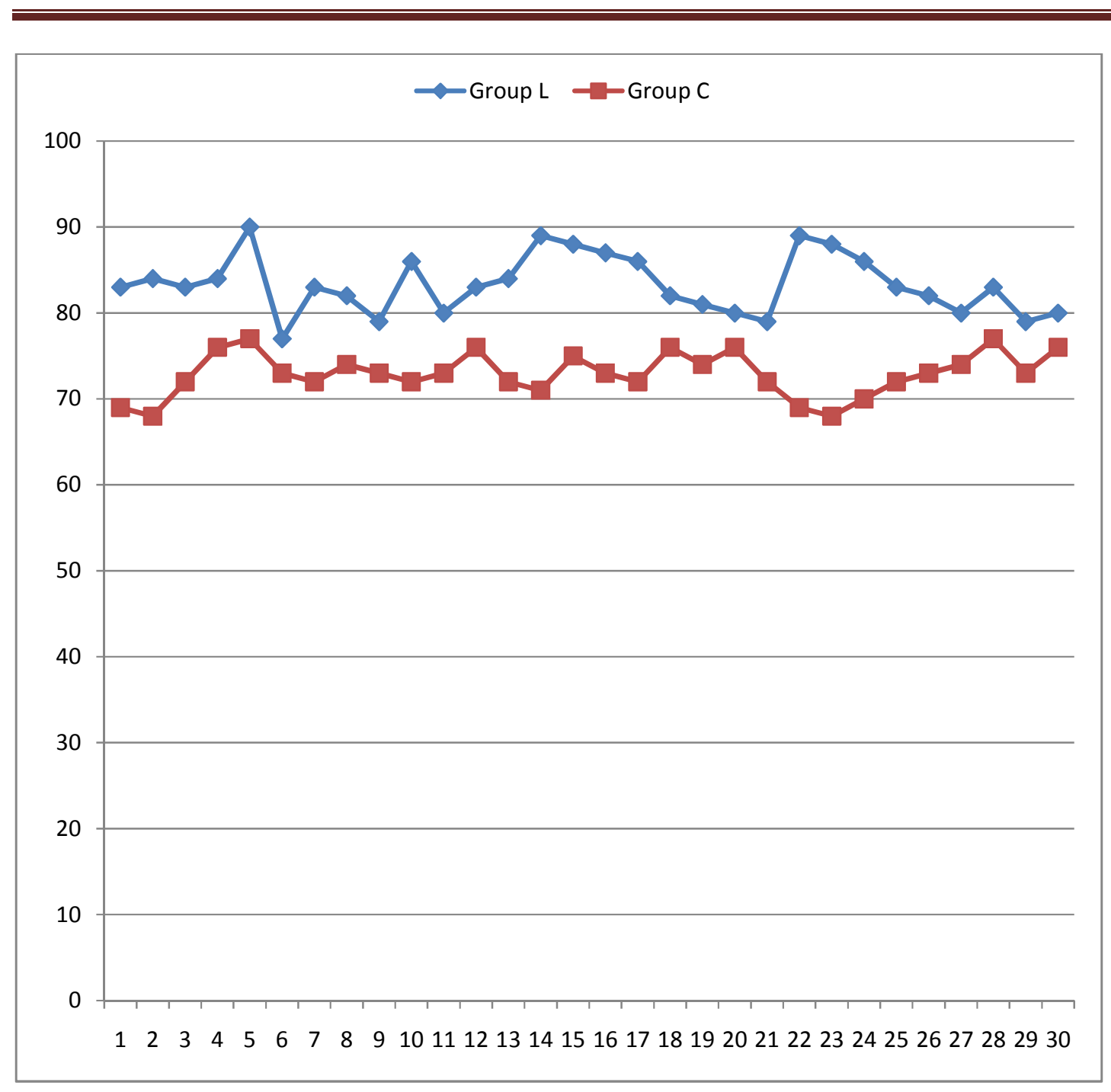

Above chart shows, better intraoperative stability in respect of heart rate in Group C, as compared to Group L. Heart rate ranged (70-80beats/min), in group C, while in group L, it was in between (80-90beats/min).

$\mathrm{X}$-axis shows: Number of patients.

Y-axis shows: Heart rate 


\section{ORIGINAL ARTICLE}

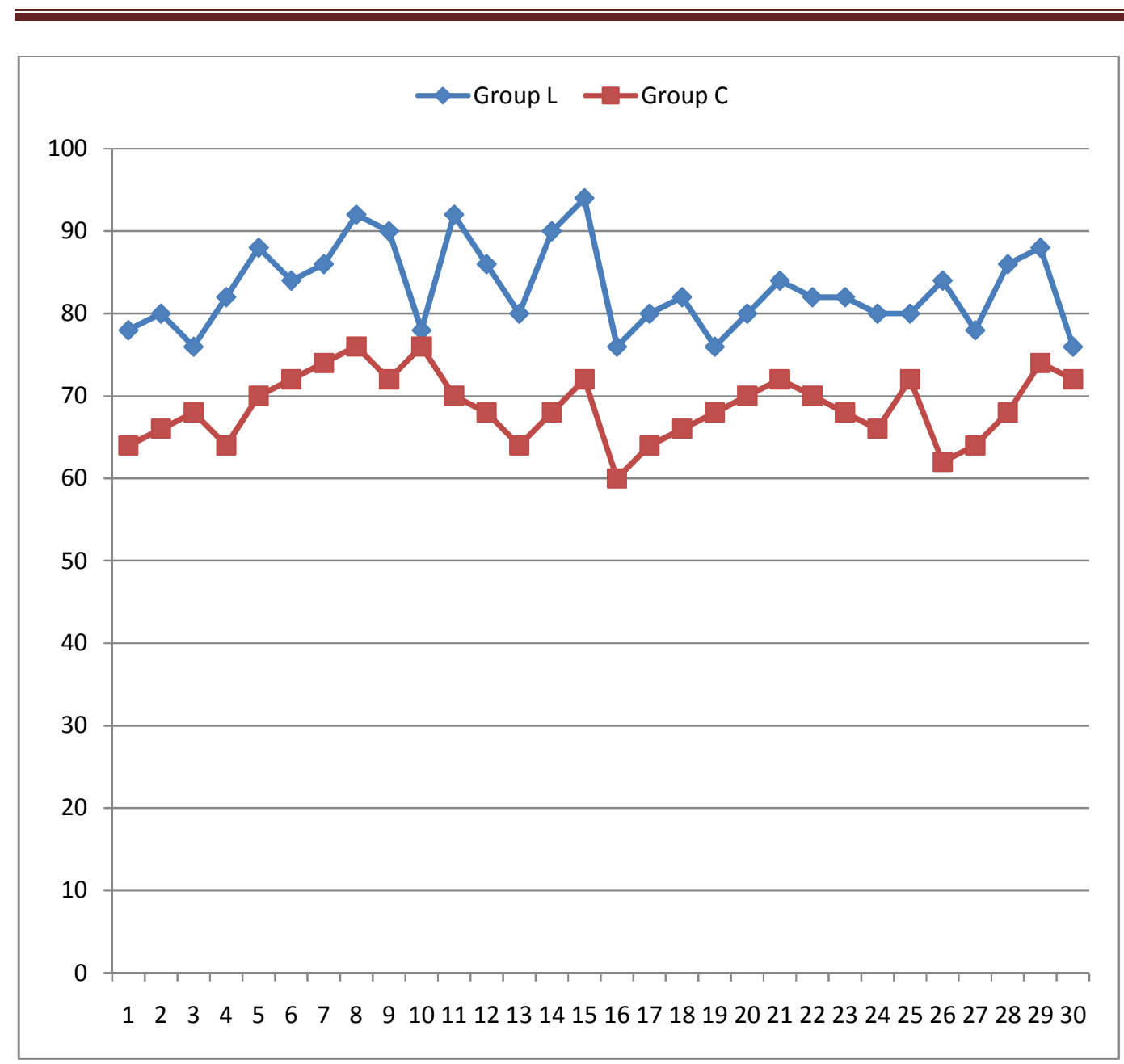

GRAPH SHOWING COMPARISON OF MAP BETWEEN TWO GROUPS

PATIENTS FROM GROUP C HAD BETTER INTRAOPERATIVE STABILITY IN RESPECT TO MAP.

$\mathrm{X}$-axis shows: Number of patients.

Y-axis shows : Mean Arterial Pressure.(MAP) 